\title{
MuCEM - et nytt nasjonalmuseum i Frankrike anno 2013
}

\section{Hvordan det nasjonale folkemuseet ble til et internasjonalt kunst- og kulturhistorisk museum}

\section{BJARNe Rogan}

Title: MuCEM - the making of a new national museum in France in 2013

\begin{abstract}
In 2007 the French national museum of popular culture (MNATP) closed its doors in Paris, to reopen in Marseilles in 2013 - as MuCEM. MuCEM's new profile is art and cultural history, and its territorial scope is the Mediterranean area. The article traces briefly the history of MNATP, through its heyday in the 1960s-70s to its downward path in the 1980s-90s. The main focus, however, is on the last ten years, which were marked by political events and external pressure more than by scholarly (ethnological) considerations. Geopolitical issues such as President Sarkozy's Union pour la Méditerranée and UNESCO's appointment of Marseilles as Europe's cultural capital for 2013 were decisive events. Finally, the text discusses what this new museum has in common with other recently established French museums, especially the Branly museum, and to what extent this rather chancy process deviated from that of other museums.
\end{abstract}

Keywords: MNATP, MuCEM, national museum, ethnology, art, aesthetics, multidisciplinarity, culture politics.

I 2013 åpnet et nytt nasjonalmuseum i Frankrike - MuCEM eller le Musée des Civilisations de l'Europe et de la Méditerranée. Som en fugl Føniks gjenoppsto det fra asken etter nasjonalmuseet for folkekultur, MNATP.

Artikkelen skisserer utviklingen av MNATP, fra en vellykket fase i de første tiårene etter krigen, gjennom en nedgangsperiode på 1980-90-tallet, og inn i en total omorganisering på 2000-tallet. MNATP var lenge den sentrale institusjonen i Frankrike for utviklingen av etnologi som vitenskapelig disiplin. Hovedvekten er lagt på reorganiseringen på 2000-tallet, som innebar både en fysisk forflytning av institusjonen - fra sentrum til periferi; en endring av det geografiske nedslags- 
feltet - fra Frankrike til regionene rundt Middelhavet (Sør-Europa, Afrika og Midtøsten); og en tematisk snuoperasjon - fra eldre, nasjonal folkekultur til en blanding av kunstog kulturhistorie. Det har betydd en forskyvning vekk fra etnologi i retning av en utpreget flerfaglighet. Det betyr også at Frankrike ikke lenger har noe nasjonalt museum for folkekultur. $^{1}$

Hva er da egentlig MuCEM - som kulturpolitisk hendelse og som politisk prosjekt? Hvor mye skyldtes resultatet intern faglig styring og hvor mye tilfeldigheter og politikk? Det er min påstand at prosessen rundt museet de siste 10-15 årene, frem til museet etter flere års stengning kunne åpne dørene i Marseille - om det da i det hele tatt kan oppfattes som det samme museet - på flere måter har vært et tilfeldighetenes spill. Teksten gir en fremstilling av prosessen rundt MuCEM og tar opp spørsmålet om hva som er spesifikt for dette museet og hva som er felles med andre franske museumsdannelser. Når denne fremstillingen har fătt et noe personlig preg, skyldes det at jeg selv har vært observatør til og deltaker i prosessen. ${ }^{2}$

\section{MARSEILLE 2013 - STARTEN PÅ ET NYTT LIV}

Den 13. januar 2013 var det mange celebriteter å se i Marseille, Frankrikes største by på middelhavskysten - en by som vel er mest kjent som kolonitidens havneby og en sydende møteplass for europeiske og afrikanske kulturer, men også for sine fattigslige bydeler, sosiale problemer og organiserte kriminalitet. Denne januardagen var president François Hollande der, i spissen for nåværende og tidligere kulturministre. Og EU-toppene var der, ledet an av Kommisjonens formann José Manuel Barroso. Anledningen var markeringen

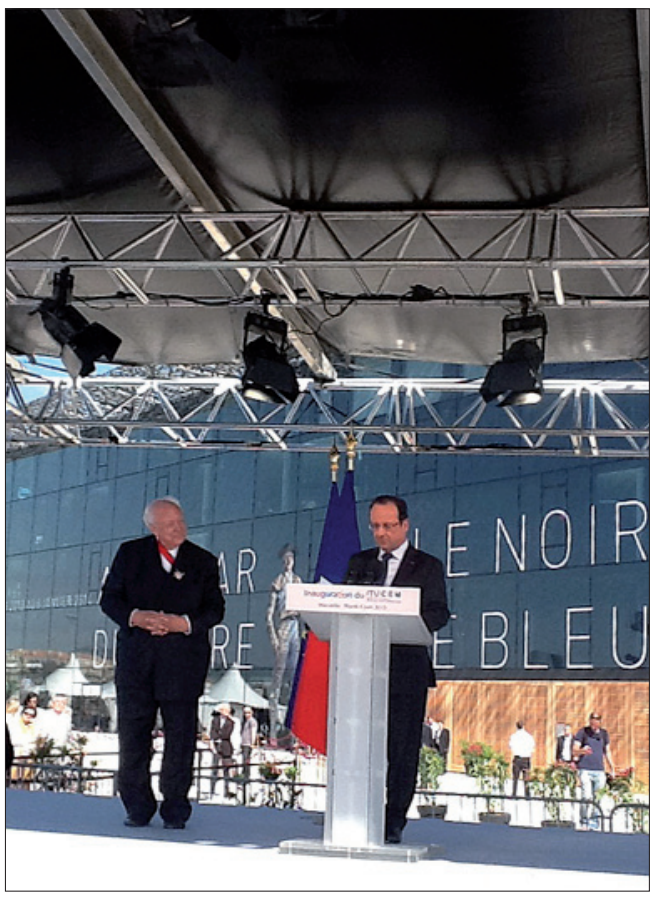

Fig.1. Marseilles borgermester Jean-Claude Gaudin (til v.) og president François Hollande under äpningsseremonien 4. juni 2013. Foto: Bjarne Rogan.

av Marseille som Europas kulturhovedstad i 2013. Hovedattraksjonen var et nytt, tomt signalbygg - MuCEM - en bygning som skulle gi Marseille dets fremste kulturpolitiske alibi.

Museet har fått en spektakulær plassering ved innløpet til byens gamle havn, på moloen der Korsika-fergene kommer og går. En moderne glass- og betongbygning føyer seg fint sammen med det gamle kystfortet - le Fort St. Jean, som er en del av museet. I tillegg har museet et stort nybygg for magasiner og restaurering på et mer tilbaketrukkent sted i Marseille. Altså nok et milliardprosjekt blant 
flere på museumssektoren i Frankrike de seneste årene. ${ }^{3}$ Selv i økonomiske krisetider tilgodeses kultur og museer i Frankrike.

Den 4. juni 2013 ble MuCEM formelt åpnet. Presidenten var tilbake i byen og ledet seremonien. Det ble en varm økt i stekende solskinn, en storslagen og - på fransk maner litt pompøs åpning. Hollandes nesten timelange tale var nærmest blottet for temaet kultur og museer. Den handlet mest om arbeidsløshet og dagsaktuelle politiske spørsmål, med invitter til Marseilles mangeårige, konservative borgermester og andre lokalpolitikere. Her er nok Hollande ulik de fleste av sine forgjengere: Franske presidenter har faktisk vært opptatt av kultur og av å etterlate seg kulturmonumenter. Så var da heller ikke MuCEM Hollandes eget verk eller representerte hans kulturpolitiske ambisjoner - om han skulle ha noen slike.

\section{ET BLIKK PÅ FORHISTORIEN}

Det er neppe mulig å forstå prosessen rundt MuCEM uten et blikk på forhistorien. Utgangspunktet er året 1937, da samlingene av fransk nasjonal folkekultur ble skilt ut fra det antropologiske Musée de l'Homme (MdH) og lagt til grunn for et nytt folkemuseum - Musée National des Arts et Traditions Populaires (MNATP). Politikken har alltid spilt med i kulissene. MNATP ble opprettet under styret til le Front Populaire (1936-38) - en venstreradikal konstellasjon som så med blide øyne på formidling av folkets kultur, i form av et "folkets Louvre". Men naziregimet som overtok i 1939 var minst like opptatt av folkelig kultur og kulturens røtter, noe som fikk betydelige konsekvenser for disiplinen - som ikke minst av den grunn skiftet navn fra folklore til ethnologie etter krigen (Boël et al. 2009).
Men MNATP beholdt sitt nøytrale navn (et kompromiss som alle mislikte!), og i over 30 år delte de to museene hus på Trocadéro-høyden i Paris, der MNATP tok seg av den franske folkekulturen og $\mathrm{MdH}$ av resten av verdens kulturer. I 1972 fikk MNATP et nybygg i Boulogne-skogen, på Paris beste vestkant. Museet hadde status som nasjonalmuseum for fransk folkekultur, men til forskjell fra de store skandinaviske folkemuseene hadde ikke museet friluftsamlinger.

Fra 1950-tallet til slutten av 1970-tallet gikk alt bra for MNATP, under ledelse av Georges Henri Rivière (1897-1985), en karismatisk skikkelse som i Frankrike og det sørlige Europa ble regnet som en fornyer av museografien (Gorgus 2003/1999). I disse tiårene spilte MNATP en avgjørende rolle for utviklingen av etnologi som vitenskapelig disiplin i Frankrike. Etnologi fikk ikke noen klar universitetsforankring før fra 1980-tallet, og museet og faget var lenge en uatskillelig helhet (Segalen 2005a). Museet innledet etter krigen et nært samarbeid med det nasjonale forskningsrådet CNRS, og på 1950-60-tallet skjedde fagutviklingen primært gjennom store feltarbeids- og innsamlingsprosjekter, der dokumentasjon, forskning, museal formidling og publisering gikk hånd $\mathrm{i}$ hånd $\mathrm{på} \mathrm{en} \mathrm{relativt}$ harmonisk måte (Segalen 2005a). I 1965 etablerte CNRS et forskningssenter ved museet - le Centre d'Ethnologie Française (CEF). CEF var landets største og mest prestisjetunge etnologiske forskningsmiljø frem til slutten av 1970-tallet (Segalen 2005b).

Men fra 1980-tallet la støvet seg over MNATP, publikum sviktet og forskerne rømte. Årsaken er sammensatt, men et vesentlig moment er at folkekulturen ikke har hatt samme identitets- og nasjonsbyggende funksjon som i Norden. Frankrike har alltid prioritert 
6 sine kunstmuseer fremfor de kulturhistoriske. Dette til tross for et kortvarig oppsving i interessen for folkelig kultur på 1980-tallet (se under). Publikum sviktet MNATP nærmest totalt, fra ca. 160000 besøkende årlig sist på 1970-tallet til under 50000 på 1990-tallet. Dette avspeilte seg i holdningene i det mektige museumsdirektoratet under Kulturdepartementet, la Direction des Musées de France, som styrte landets nasjonalmuseer med jernhånd. Der interesserte man seg lite for et folkemuseums skjebne.

Men også forskningsenheten CEF, som var administrativt selvstendig og finansiert av forskningsrådet CNRS, fikk problemer. Mens museet holdt fast ved en etnologi der materiell kultur, teknologi og førindustrielle samfunnsforhold sto i fokus, utviklet forskerne ved CEF faget i retning av et mer samtidsorientert studium av sosiale relasjoner og immaterielle temaer - som religion, slektskap, urbanisme, identitet og lignende. Gnisningene mellom museets fåtallige samlingsansvarlige konservatorer og de mange frie CEF-forskerne ble påtagelig. Rundt 1980 hadde CEF vokst seg større enn resten av museet, med drøyt 60 forskere og teknikere uten formelt ansvar for museets virksomhet (Segalen 2005a:222, 2005b). Klimaet ble jevnt dårligere, og disse fulltidsforskerne forlot i stigende grad CEF til fordel for andre forskningssentre. CEF ble nedlagt i 2005. I 2007 stengte MNATP dørene i Paris.

\section{DEN NÆRE HISTORIEN - ØKOMUSEENE OG LE PATRIMoine}

På 1980-tallet hadde to nye utfordrere gjort livet ekstra vanskelig for MNATP, nemlig økomuseene og en ny kulturarvspolitikk. Mens det meste gikk galt for det Paris-baserte MNATP, ble 1980-tallet en oppgangstid for lokale kulturhistoriske museer. Det gjaldt spesielt en nykomling som økomuseene - et fenomen som går tilbake til 1970-tallet. Frankrike var økomuseumfilosofiens hjemland, og 1980-tallet var økomuseenes tiår.

Hva var egentlig økomuseene? De har vært omtalt som 68-generasjonens museumsutopi, et angrep på de etablerte museenes stivnede representasjoner og et forsvar for lokalbefolkningers egen kultur og eget engasjement, spesielt i områder preget av avfolkning og industrinedleggelse. Bearbeiding av egen kultur skulle erstatte utstillingsmontre, praktgjenstander og sovende magasinsamlinger. Altså ideologisk sett ikke så ulikt den samtidige lokalhistoriske "Grav der du står"-bevegelsen vi kjenner fra Norden, som skulle gi vanskeligstilte lokalsamfunn deres verdighet og identitet tilbake.

Gjennom økomuseene og de beslektede regionalparkene ble den levende, lokale folkelige kulturen satt i fokus og ofte på en heldig måte knyttet opp mot lokalt næringsliv og turisme. Dette foregikk altså samtidig med at publikum i Paris vendte ryggen til bondekulturens praktgjenstander og en stivnet representasjon av en "nasjonal" folkekultur, slik den fremsto i MNATP.

1980 - det offisielle Kulturarv-året i Frankrike - var et vendepunkt for både MNATP og faget. Det året ble "den etnologiske kortstokken "ble" delt ut på nytt", for å sitere Martine Segalen (2005a). Med et departementalt pennestrøk ble folkekultur innlemmet $\mathrm{i}$ "kulturarven" (le patrimoine) - i et utvidet kulturarvsbegrep. Kulturdepartementet opprettet en sentralisert institusjon, la Mission du patrimoine ethnologique, og ga det et romslig budsjett.

Le Patrimoine, som institusjonen ble kalt, ble en suksesshistorie for etnologene. Den har gjennom årene initiert og finansiert en serie 
prosjekter om landsbygdas kulturformer, arbeider- og bykultur, tradisjonelle ferdighetsog kunnskapsregimer o.l. Rådet finansierte en rekke vitenskapelige monografier og antologier, samt det etnologiske tidsskriftet Terrain, som publiserer forskning om nyere temaer. ${ }^{4} \mathrm{Le}$ Patrimoine, som var rettet mot dokumentasjon, forskning og (aksjonsorientert) formidling, skapte på 1980-90-tallet et betydelig arbeidsmarked for fransk etnologi.

Men le Patrimoine's virksomhet fremsto etter hvert som en bredt anlagt redningsaksjon for en utdøende folkelig kultur, og de sentraldirigerte prosjektene kom ofte i konflikt med et mer kritisk og refleksivt etnologifag, der ikke minst kulturarvsindustrien i seg selv kom i søkelyset. Mot årtusenskiftet løp en debatt om denne "statlige politiseringen" av kulturarven (Tornatore 2004), og resultatet var at le Patrimoine ble nokså vingeklippet. Dette kulturpolitiske organet eksisterer fortsatt - fra 2005 under navnet la Mission à l'Ethnologie men med et redusert aktivitetsnivå.

Le Patrimoine’s virksomhet på 1980-90-tallet betydde mye for ekspansjonen og utviklingen av fransk etnologi. Men samtidig bidro denne institusjonen ganske effektivt til MNATPs lidelseshistorie (Segalen 2005a). Den medførte en forskyvning av de totale ressursene - i form av både oppmerksomhet, bevilgninger og forskning - vekk fra sentrum og vekk fra nasjonalmuseet i Paris.

Også MNATPs andre konkurrent, økomuseene, er kommet i vansker. Alt på 1990-tallet mistet bevegelsen vind i seilene, og på 2000tallet sliter de fleste økomuseene tungt. Noen har gått inn i omstillingsprosjekter, og enkelte har gått tilbake til å kalle seg museer, for å unngå å assosieres med et vanskeligstilt område. Bevegelsen var tuftet på en demokratisk idé om lokalbefolkningens frivillige deltakelse, men den utopien holdt ikke lenge. Kontinuer-

lig museumsdrift krever profesjonell bistand, administrasjon, vedlikehold og fornyelse av kunnskap. Økomuseene har møtt harde økonomiske realiteter, og det virker som om både lokalbefolkning og turister har gått litt lei av de mange representasjoner av identiteter - det være seg historiske eller samtidige (Segalen 2005a:304-305).

\section{NY KURS FOR MNATP}

Erfaringene var altså ganske entydige. MNATP var på vei utfor bakke allerede fra ca. 1980, og museets to konkurrenter, økomuseene og le Patrimoine, skulle også oppleve en nedtur - svakt på 1990-tallet og mer brutalt etter årtusenskiftet. Det ble igjen åpenbart at folkekulturen ikke sto særlig høyt i kurs i Frankrike, i motsetning til les beaux arts kunsten og finkulturen.

På 1990-tallet virket MNATPs snarlige død overhengende. Museumsdirektoratet mente sikkert med rette - at pasienten var så syk at redningen ikke kunne komme innenfra, og i dette tiåret skiftet museumsledelsen fem ganger (Rogan 2003a, 2003b, Segalen 2005a, 2013). Flere eksterne ble satt på som direktører for å finne en vei ut av uføret. Den mest radikale planen kom fra etnologen Jean Guibal, som hadde ledet en vellykket snuoperasjon for fylkesmuseet i Grenoble. Guibal ønsket at MNATP skulle bli en kulturell møteplass, mer enn en forskningsinstitusjon, fokusere mer på samtiden og igjen gå sammen med le Musée de l'Homme til et museum for alle verdens kulturer. Med sin kjennskap til Museumsdirektoratets detaljstyring (se under) stilte Guibal krav om autonomi i administrasjons- og budsjettsaker. Men de ansatte ved begge museene protesterte mot sammenslåing og Direktoratet sa 
nei til autonomi. I ettertid har mange beklaget at en slik fusjon ikke fant sted; Branly, som overtok det meste av MdHs samlinger, kunne ha fått en interessant faglig profil dersom det franske og det europeiske hadde blitt integrert med det eksotiske. ${ }^{5}$ Jean Guibal valgte å trekke seg og returnerte til Grenoble.

Andre utredninger ble gjort og ledere kom og gikk. Da Michel Colardelle, arkeolog og kulturpolitiker med tilknytning til flere sosialist-regjeringer, ble ansatt som direktør i 1997 , begynte ting å skje. Hans plan gikk i grove trekk ut på å skape et museum som dekket franske kulturer - i flertall - fra middelalderen til i dag, med vekt på samtid og dagens utfordringer, men med en klar forskningsprofil. Han ville ha en mer sentral beliggenhet i Paris for museet. Dermed begynte en nesten 15 år lang kamp mot byråkrati og fagforeninger, mot et mektig direktorat og uinteresserte politikere - og mot deler av staben som tviholdt på arven fra Rivière.

Men en ny tomt sentralt i Paris lot seg ikke oppdrive. Colardelle falt ned på en løsning som innebar to radikale brudd med fortiden, nemlig å omgjøre det til et museum for europeiske kulturer - etter forslag fra den franske etnologen Isac Chiva, og å flytte museet ut av Paris. Tanken om å omgjøre et museum for nasjonal kultur til et museum for europeiske kulturer kan synes overraskende, men på slutten av 1990-tallet fantes det presedenser; Berlin hadde allerede gjort det, Brussel var i ferd med å etablere et Europa-museum, og Italia lekte med tanken (jf. Rogan 2003c, Mazé 2008, 2010).

Utflytting av et nasjonalmuseum fra Paris var egentlig en uhørt tanke - i et av Europas mest sentraliserte land, men et statlig desentraliseringsprosjekt (2002/2003) og en ny museumslov (2002) gjorde det mulig. Collar- delle gjorde først resultatløse fremstøt mot Lille (Nord-Frankrike) og mot Lyon (SørøstFrankrike), men endte opp helt i sør, i Marseille. Når valget falt på Marseille skyldtes det flere årsaker. Det gamle fortet St. Jean tilhørte staten, og staten ønsket å finne en ansvarlig institusjon som kunne drifte det. Samtidig sto byutviklingsselskapet Euroméditerranée ${ }^{6}$ - et konsortium bestående av staten, lokale og regionale myndigheter og investorer - foran en storstilt utbygging av havneområdene i Marseille, inklusive området for museet. Marseille pekte seg positivt ut, og den statlige medvirkningen i dette urbanismeprosjektet virket betryggende. Men valget av Marseille skulle gi uante føringer. Et museum for europeiske kulturer er i seg selv et komplisert prosjekt, og plasseringen helt i utkanten av Europa skulle ikke gjøre det enklere. Det var i denne fasen navnet på museet ble utvidet - Méditerranée ble lagt til Europa.

Den nye museumsloven (2002) opprettholdt en svært sterk statlig styring med landets museer, spesielt nasjonalmuseene. Kulturdepartementets ene sterke vaktbikkje var la $D i$ rection des Musées de France (DMF), i 2009 erstattet av le Service des Musées de France (SMF), som i praksis styrer landets ca. 1200 klassifiserte museer, gjennom koordinering av vitenskapelig og pedagogisk aktivitet. ${ }^{7}$ Den andre er la Réunion des Musées Nationaux (RMN), som har full kontroll med de 30-40 nasjonalmuseene. RMN finansierer og godkjenner aksesjoner (innkjøp og donasjoner), har ansvar for alle midlertidige utstillinger og finansierer og utgir museenes kataloger og vitenskapelige publikasjoner.

MNATP/MuCEM skulle få god føling med dette statlige styrings- og kontrollapparatet og med hvordan de to etatene prioriterte kunst fremfor folkelig kultur. 


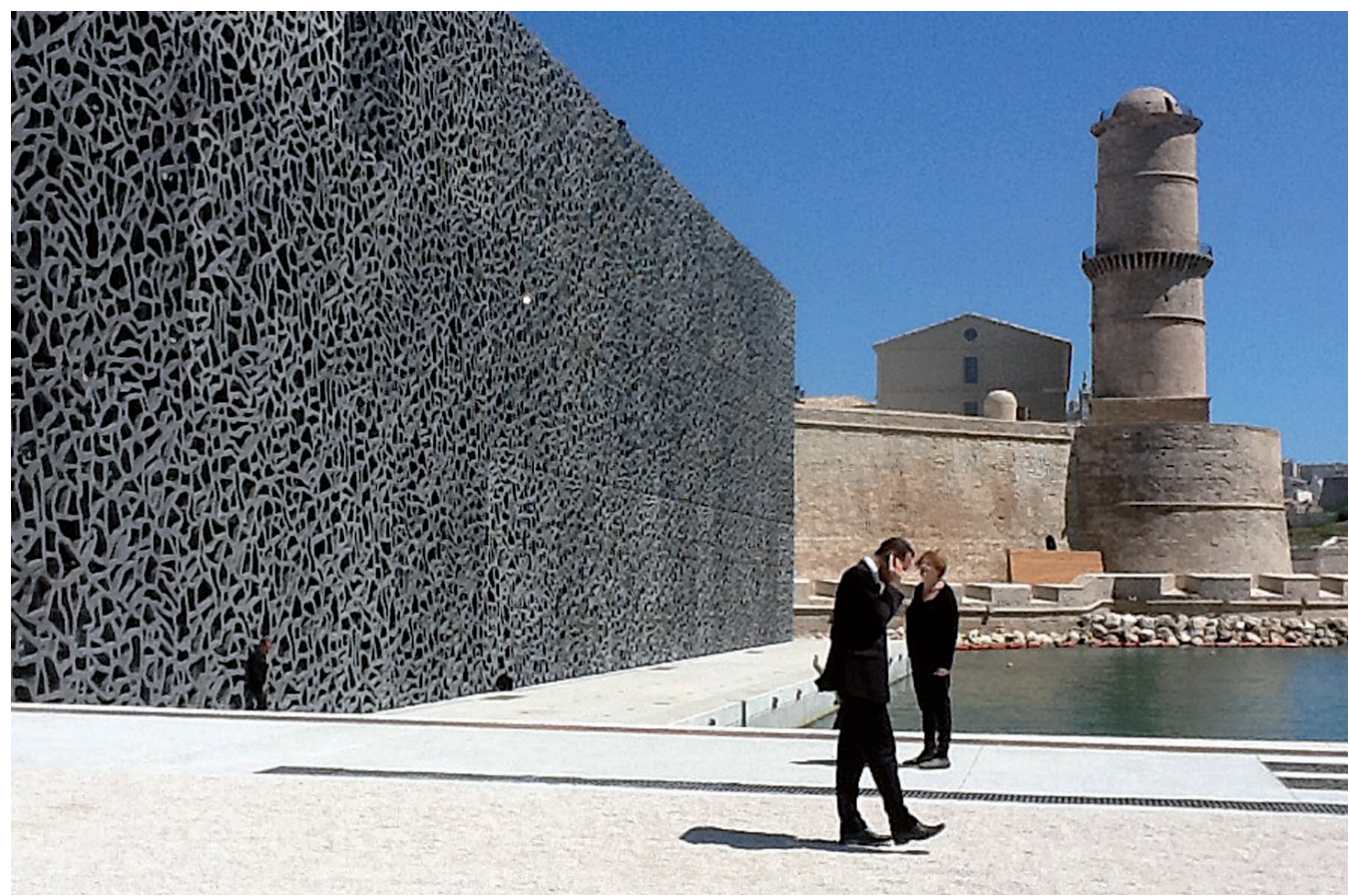

Fig. 2. MuCEMs nye bygning, tegnet av Rudi Ricciotti, og den eldre delen av museet, le Fort St. Jean, som vokter innlopet til den gamle havnen. Full beredskap for president François Hollande ankommer. Juni 2013.

Foto: Bjarne Rogan.

\section{FRANSK KULTURPOLITIKK OG FRANSKE PRESIDENTER}

I hvilken grad hadde dette museumsprosjektet politiske overtoner på nasjonalt nivå? Frankrike vekslet i perioden mellom konservative regjeringer og sosialistregjeringer. Et periodevis vanskelig samboerskap mellom en konservativ president og sosialistregjeringer kompliserte situasjonen. Fra 1995 til 2007 var den konservative Jacques Chirac landets president. Chirac var så sterkt og personlig opptatt av "primitiv kunst" fra den tredje verden - som han dessuten selv samlet på - at han fikk opprettet et nytt antropologisk kunstmuseum i Paris, le
Musée du quai Branly (Price 2007, 2011, Rogan 2008, 2010). Denne prosessen innebar nedlegging av to andre nasjonalmuseer $\mathrm{MdH}$ og "Kolonimuseet" - le Musée des Arts de l'Afrique et de l'Océanie (MAAO). MuCEM kom $i$ et noe ugjennomsiktig konkurranseforhold til dette president-styrte museumsprosjektet, fordi det ikke var gitt at landet hadde råd til å etablere to tunge nasjonalmuseer samtidig. MuCEMs styre, og ikke minst den forhenværende sosialistpolitikeren Michel Colardelle, fulgte intenst med hver gang det var regjeringsskifte eller ministerskifte i kulturdepartementet.

Det er vanskelig å si hvilke konkrete konse- 
10 kvenser president Chiracs preferanser hadde i praksis. Konkurransen med Chiracs museum betydde i seg selv trolig bare en forsinkelse av MuCEM-prosjektet. Colardelle selv hevdet jevnlig at det lå politiske motiver bak de stadige budsjettproblemene og andre former for trenering. Den raske gjennomføringen av Branly-prosjektet (åpning juni 2006) og seigpiningen av MuCEM gir i det minste indikasjoner på hvor kulturbyråkratiets lojalitet lå. Mange av oss som fulgte prosessen på nært hold oppfattet likevel dette primært som et uttrykk for hovedregelen om at kunst blir prioritert og folkekultur neglisjert av det franske embetsverket, et ytterst homogent korps med utpreget finkulturell orientering. Det forholdet at Branly-prosjektet etter hvert tydelig vendte seg vekk fra antropologi og i retning kunst, bidro utvilsomt til at Branly vant et helt annet gehør i direktoratet enn MuCEM gjorde, som forsvarer av folkekulturen. ${ }^{8}$ Branly fikk dessuten en mer autonom status, slik også kunstmuseet Louvre hadde.

Fra 2007 til 2012 var den konservative Nicolas Sarkozy president. Sarkozy var den første av etterkrigstidens presidenter som ingen assosierer med kultur.' Han hadde neppe noen personlig interesse for museer generelt eller for MuCEM spesielt. Men MuCEM skulle vise seg å bli politisk viktig for hans europapolitikk, og hans kulturminister fattet etter hvert interesse for prosjektet - når et par kulturpolitiske brikker først var falt på plass.

\section{USIKRE ÅR OG TILFELDIGHETENES SPILL}

Hele det første tiåret på 2000-tallet bød på usikkerhet og motgang for museumsprosjektet - økonomisk, administrativt og politisk. Det gamle fortet St. Jean tilhørte staten og kunne disponeres, men tomten i sjøkanten var byens eiendom. Marseille, som absolutt ikke var kjent som noen kulturby, var ikke begeistret over tanken på å avgi byens flotteste tomt til et museum. En arkitektkonkurranse ble likevel utlyst i 2004 og vinner utpekt - i en prosedyre der de faglige instansene hadde lite de skulle ha sagt. MuCEMs ledelse var svært lite begeistret for vinnerutkastet. Etter det sto alt lenge stille. Problemet var ikke bare myndighetene på riksnivå, men også likegyldigheten blant byens og regionens politikere - og ikke bare når det gjaldt finansieringen. ${ }^{10}$ Mange av aktørene valgte å forlate et prosjekt som syntes å ha få utsikter til å lykkes.

Flere tilfeldige begivenheter var avgjørende for at museet klarte å bite seg fast på moloen. Da den prestisjetunge America's Cup i seiling i 2007 for første gang skulle avvikles i Europa, satset byens politikere alt på seilsporten. Marseille søkte om vertskapet, tilbød å bygge ut havneområdet (inklusive museumstomten) for seilsport, brente av 50 millioner $€$ av statlige midler på søknaden og tapte til fordel for Valencia, til stor tilfredshet for MuCEMs ledelse.

Men høsten 2008 slo finanskrisen til og den franske stat trakk i den økonomiske nødbremsen, frøs museets driftsbevilgninger og la hele prosjektet på is. Som i andre land ble det laget redningspakker, som stort sett gikk til å berge konkurstruede banker. I kulturlandet Frankrike derimot gikk en del av redningspakken til truede kulturprosjekter, deriblant MuCEM.

Den helt avgjørende redningsplanken kom da UNESCO i 2009 utpekte Marseille til Europas kulturhovedstad for året 2013. Som en by nokså fattig på kulturinstitusjoner måtte man plutselig se seg om etter kulturelle alibier, og museet var inne i varmen igjen. Bak denne avgjørelsen lå det tunge forhandlinger. Frankrike konkurrerte i siste runde med ett 
annet land og tre franske byer konkurrerte internt. Statsminister og kulturminister engasjerte seg - først for Frankrike, deretter for Marseille. I den endelige runden var det klart at uten et nytt MuCEM ville Marseille - og trolig Frankrike - tape kampen om den attraktive statusen som Europas kulturhovedstad. Kulturministeren garanterte at MuCEM skulle stå ferdig i 2013. ${ }^{11}$ En av museets direktører sa det slik: "Det som reddet prosjektet var utpekingen til kulturhovedstad - uten det hadde det aldri blitt noe MuCEM."12 En annen av museets konservatorer og mangeårig styremedlem formulerte det spissere og mer folkelig: "Da ble MuCEM trukket opp av søppelbøtta igjen."13

Også en annen uforutsett faktor trakk i samme retning og styrket ytterligere $\mathrm{Mu}$ CEMs posisjon i siste fase. Med Angela Merkels stadig mer dominerende posisjon i NordEuropa satset president Nicolas Sarkozy på et sterkere fransk politisk hegemoni i det sørlige Europa og middelhavsregionen. I 2008, da Frankrike hadde presidentskapet i EU, lanserte Sarkozy Unionen for Middelhavsregionen (l'Union pour la Méditerranée), en mellomstatlig organisasjon som skulle knytte sammen EU og landene som grenset til Middelhavet. Tanken var å etablere et tyngdepunkt i sør med et fransk hegemoni. Formelt dekket ikke unionens ansvarsområde kultur. Men et fransk politisk hegemoni impliserer alltid kultur, og Frankrike trengte nå mer enn noensinne en prestisjefylt kulturinstitusjon i sør.

Det var altså en rekke fageksterne forhold og uforutsette begivenheter - America's Cup, finanskrisen, redningspakken, UNESCOs kulturbystatus, middelhavsunionen - som gjorde MuCEM til et nærmest 'jojo-prosjekt': den ene dagen tja eller nei, den andre dagen ja.
MED RYGGEN MOT EUROPA OG BLIKKET

Utgangspunktet tidlig på 2000-tallet for et museum for europeiske kulturer var ikke dårlig. Tyngdepunktet i det gamle MNATPs samlinger lå på det midtre og nordlige Frankrike. Videre ble det tidlig bestemt at MNATP ved "parteringen" av MdH skulle overta dette museets europeiske samlinger (blant annet de nordiske), mens samlingene fra fjernere kulturer ble overført til Branly. For det tredje tok en del av innkjøpene til samlingene på 2000-tallet sikte på å dekke "lakuner" spesielt i Sentral- og Øst-Europa. Og i samsvar med Europa-planene var opprinnelig et stort antall personer i $\mathrm{MuCEMs}$ vitenskapelige råd (etter hvert ganske inaktivt) og flere i styret oppnevnt med tanke på en bred dekning av Europa. ${ }^{14}$

Men det sørlige Frankrike og middelhavskysten var dårlig dekket i samlingene, og dette skulle bli et følbart problem etter at Marseille ble valgt som lokalisering. En sterkere orientering mot Middelhavet ble et tilbakevendende tema i diskusjonene, og i styret og innkjøpskomitéen opplevde vi stadig føringer med hensyn til museets fremtidige geografiske nedslagsfelt - middelhavsregionen. Det kom ikke noen klar marsjordre fra Paris før rundt 2008-09, men med valget av Europas kulturhovedstad og planene for en middelhavsunion tok departementet et fast grep om styringen av museumsprosjektet. I 2009 ga departementet utvetydig beskjed om at MuCEM skulle "reorienteres" for å kunne inngå i planene for Middelhavsunionen. ${ }^{15}$

Fra da av merket vi godt i innkjøpskomiteen hvordan fokuset ble flyttet mot sør. MuCEM var ikke lenger et Europa-museum annet enn litt diffust i navnet. I tillegg til den 
12 europeiske siden av Middelhavet (med en avstikker til Svartehavet) skulle museet dekke Nord-Afrika, Midtøsten og de nærmeste kulturer østover.

Når det gjaldt den faglige profilen, fjernet man seg mer fra det tradisjonelle etnologiske feltet. I innkjøpskomiteen fikk vi presentert stadig flere kunstobjekter for innkjøp, og enkelte ganger spøkte vi med at vi konkurrerte med Louvre. I 2010 skrev kulturministeren eksplisitt at kunst skulle ha en bred plass i museets "tverrfaglige virksomhet" ${ }^{16}$, og ikke lenge etter ble det opprettet en stilling ved museet for en konservator i samtidskunst. Det hører med til historien at (de fleste) franske nasjo- nalmuseer har liten grad av autonomi i innkjøpssaker. Hovedparten av budsjettet og godkjenning av større innkjøp og innsamlingsprosjekter er trygt plassert i direktoratet (RMN). Det samme gjaldt tilsettinger.

Direktør Colardelle måtte svelge atskillige kameler i denne prosessen, og han kom jevnlig på kant med direktoratet og departementet. I denne stressede situasjonen ble både han og museet handlingslammet, og det kan diskuteres om han alltid reagerte adekvat på presset. Staben ga ham heller ikke mye hjelp, splittet som den var i synet på både utflytting fra Paris og faglig profil. Departementet lot foreta en ekstern evaluering av prosessen - ledet av pre-

Fig. 3. Den elegante gangbroen som binder den nye museumsbygningen sammen med Fort St. Jean, som inneholder både utstillingslokaler, restauranter og utearealer. Januar 2013. Foto: Bjarne Rogan.

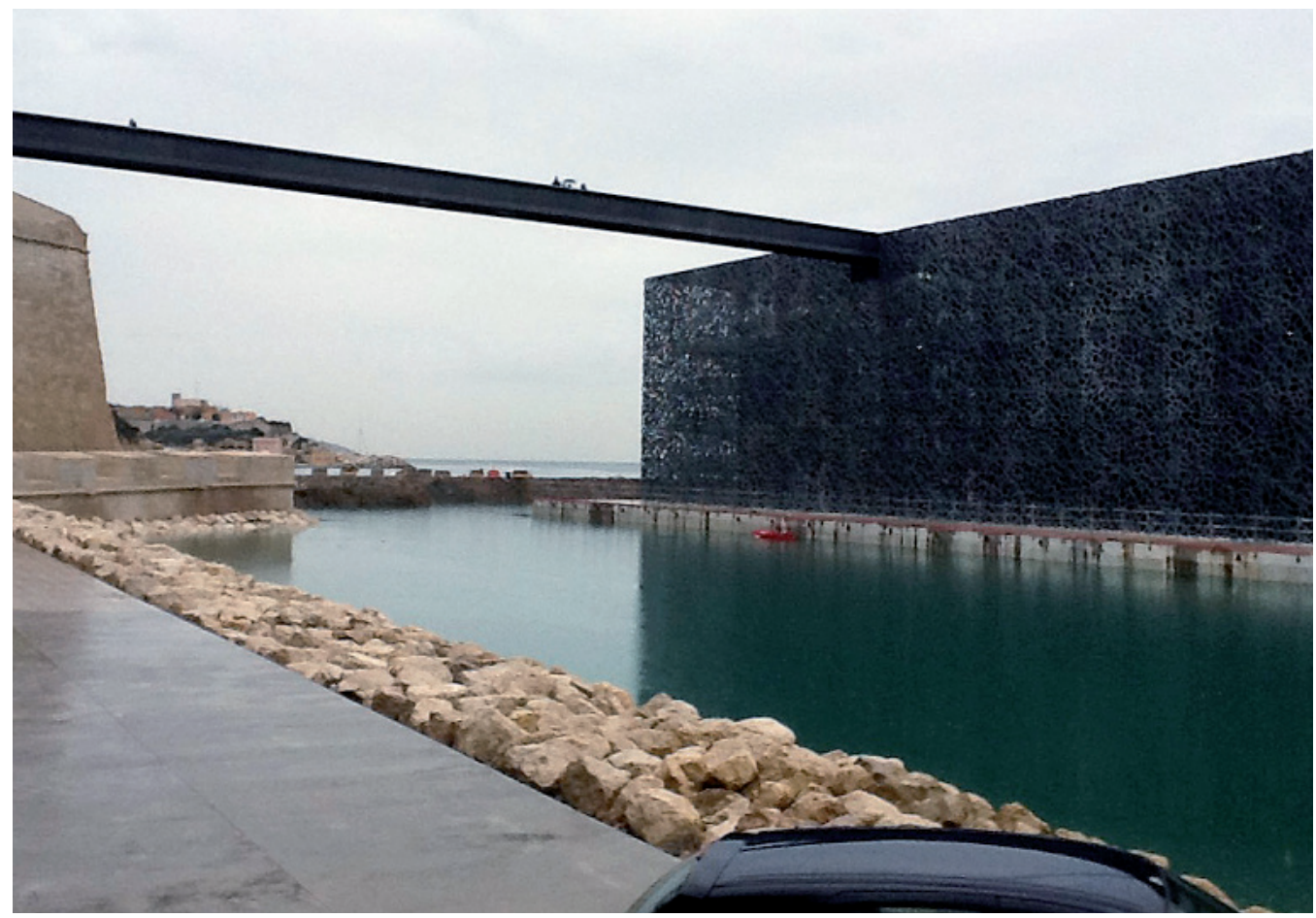


sidenten for Branly. Rapporten ble hemmeligstemplet og ikke en gang forelagt styret - offisielt. Innholdet var tilsynelatende ikke så negativt for MuCEM, men ikke så lenge etter måtte Colardelle ta sin hatt og gå. Da han nektet å ta imot en retrettstilling som samlingsansvarlig, fant Kulturdepartementet det i 2009 for godt å "forfremme" ham til fylkeskultursjef i Fransk Guyana - i Sør-Amerika. Forskeren og museologen Michel Colardelle ble skiftet ut med Bruno Suzzarelli, en administrator med bakgrunn fra Frankrikes mest prestisjetunge høyskole for administrative ledere (ENA).

Middelhavsprofilen ble nå offisiell politikk, kunsten - inklusive og samtidskunsten - skulle få sin plass, og fra da av gikk tingene nesten på skinner frem til åpningen våren 2013.

\section{SUKSESS - TIL SLUTT}

Vi er tilbake i 2013. Hva ble så resultatet av nesten 15 års usikkerhet, kursendringer - og påtrykk fra maktens senter? Først og fremst en publikumssuksess - og det var ingen opplagt sak. MuCEM hadde $\mathrm{i}$ årene før åpningen hatt mindre utstillinger i hovedbygningen oppe på fortet. Generalprøven var i 2007, med utstillingen Trésors du quotien - Hverdagslivets skatter, en utpreget etnologisk utstilling som skulle vise Marseilles befolkning praktobjekter fra det gamle MNATP - fra folkedrakter til redskaper og annen folkekunst. Utstillingen ble slaktet i pressen og publikum uteble. Depresjonen bredde seg nok en gang i staben og flere så seg om etter stillinger andre steder. Samtidig sendte den et alvorlig varsel om hvilken kurs museet ikke burde velge.

Men i dagene etter åpningen 4. juni 2013 strømmet publikum til, og fasit etter de første fem-seks månedene sier sitt: 1,5 millioner be- søkende, hvorav en halv million betalende i utstillingene. De øvrige avgrenset besøket til museets attraktive utearealer (ca. 15 mål), kafeen og restauranten på det flott restaurerte fortet.

Den nye hovedbygningen i glass og betong, en kvadratisk kloss på ca. 70 x 70 meter tegnet av Rudi Ricciotti, er blitt en publikumsmagnet. Kombinasjonen av nybygget og den gamle festningen gir en særegen opplevelse. Den nye bygningen er spektakulær og - i hvert fall eksteriørmessig - en suksess, selv om den ikke er optimal for museumsformål. Blant annet slipper de indre glassveggene inn mer av Middelhavets skarpe sollys enn hva de ytre gitterveggene i betong klarer å absorbere. Store veggflater i utstillingslokalene måtte derfor bekles med gardiner.

Når det gjelder utstillingene, har man svært langt på vei latt gjenstandsmaterialet fra MNATP forbli i magasinene, som er delvis åpne for publikum i en tilbaketrukket bygning i Marseille, der også restaureringsavdelingen er plassert. Noe av det gamle gjenstandsmaterialet er aktivisert i mindre utstillinger i lokaler i fortet. I hovedbygningen vises to semi-permanente utstillinger som skal skifte med tre til fem års intervaller. Den ene er Middelhavsgalleriet, et forsøk på en kulturhistorisk orientert illustrasjon av noen sentrale temaer fra det mediterrane området - som innføringen av jordbruk, utviklingen av byer og demokrati, og "oppfinnelsen" av guder. Den andre er om de monoteistiske religionene - kristendommen, jødedommen og islam, med utgangspunkt i Jerusalem.

Den andre halvparten av utstillingsarealet er forbeholdt to midlertidige utstillinger som skal skifte hvert halvår. Høsten 2013 tok disse opp historiske og samtidsorienterte temaer fra det mediterrane området: Den ene kjønnsrol- 
14 ler, den andre sivilisasjonenes utvikling versus kriger og barbari, frem til borgerkrigene i Libanon og Syria.

Middelhavsprofilen gjenspeiles også i offentlige forelesninger knyttet opp mot de midlertidige utstillingene. Og for å understreke middelhavskonteksten er museets store auditorium oppkalt etter antropologen Germaine Tillion, som mer enn noen annen arbeidet med relasjonene mellom Nord-Afrika og Frankrike.

Det faller utenfor artikkelens rammer å foreta noen utstillingsanmeldelse. Men utstillingen Kjonnenes basar - feminint/maskulint rundt Middelhavet var for undertegnede den mest innovative og spennende. Og den skapte desidert mest debatt og engasjement, nettopp på et tidspunkt da Frankrike kokte på grunn av loven om ekteskap mellom personer av samme kjønn. Det minst overbevisende - for undertegnede - var Middelhavsgalleriet.

MuCEM har i sitt første halvår holdt et hesblesende aktivitetsnivå, med konferanser, filmvisninger og andre bredt anlagte publikumsarrangementer, og dessuten en rekke vitenskapelige seminarer. Museet vedgår åpent at Musée du Quai Branly har vært modellen for den utadrettede profilen.

Alt i alt: MuCEM har fått en mottakelse som overgikk selv de mest optimistiske spådommer - og de var det ikke så mange av de siste par årene før åpningen. Pressen har gitt en begeistret (og påfallende ukritisk) dekning, og Marseilles befolkning har på kort tid beveget seg fra likegyldighet til entusiasme. Byens politikere med borgermester Jean-Claude Gaudin i spissen, som lenge var skeptiske eller regelrett negative til prosjektet, har glemt sin motstand og skryter til dels uhemmet byens nye attraksjon. ${ }^{17}$ MuCEM synes å ha hatt en klar Bilbao-effekt på byen, om vi skal tro næ- ringslivets og politikernes oppsummering etter det første halve året. Så får heller franske etnologer beklage at det ikke lenger finnes noe nasjonalt etnologisk museum i landet.

\section{TILFELDIGHETER, MEN OGS§ MØNSTRE?}

Jeg har ovenfor pekt på at prosessen frem til åpningen fortonet seg som et nokså tilfeldig spill for de som opplevde den på nært hold, og jeg har hevdet at resultatet ble en suksess. Begge påstandene kan nyanseres. Selv om det kan oppfattes som noe nær et mirakel at museet ble "trukket opp av søppelbøtta igjen", reflekterer MuCEM en del generelle trekk ved museumsutviklingen i perioden, $i$ det minste $i$ Frankrike. Og selv om publikumstilstrømningen i starten peker mot en braksuksess, er det flere usikkerhetsmomenter fremover.

Tendensen til a nedtone den nasjonale kulturen er kanskje ikke så overraskende, i et land der folkekulturen aldri har vært noen kassasuksess. Til det kommer den postkoloniale antropologiske innsikten at man ikke kan representere en gitt kultur i dens fulle bredde verken andres kulturer eller egen. Det er nærliggende å sammenlikne de to museene som ble drevet frem parallelt, Branly med utgangspunkt i MdH og MuCEM på basis av MNATP. Verken MNATP eller MdH var opprinnelig ment som utstillingsinstitusjoner. De var sene representanter for det museale paradigmet som oppsto på 1800-tallet og som gjerne kalles det "ensyklopediske". Gjennom systematisk innsamling skulle de dokumentere henholdsvis Frankrikes (materielle) kultur og verdens (materielle) kulturformer. De skulle akkumulere og lagre data med tanke på dokumentasjon, og ikke primært stå i dialog med et publikum. Branly brøt eksplisitt og høylydt med MdHs gamle linje. Og MuCEM 


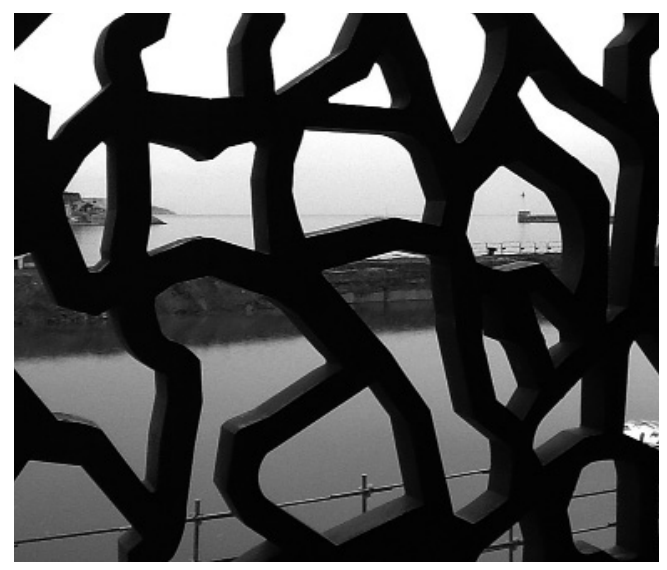

Fig. 4. Det luftige betonggitteret i ytterveggen. Mellom denne ytterveggen og den indre glassveggen gär det brede passasjer og trapper for publikum. Juni 2013. Foto: Bjarne Rogan.

bryter med en forståelse av fransk kultur som en avgrenset eller avgrensbar enhet og med troen på at det er mulig å rekonstruere en nasjonal identitet. MuCEM velger i stedet å presentere noen få elementer - fra det mediterrane området (i Middelhavsgalleriet) og i form av temautstillinger om kjønn, religion og krig, alt på tvers av nasjonale kulturer. Dersom museet hadde insistert på å gjenoppstå som et mer eller mindre ensyklopedisk museum for fransk kultur, er det svært lite sannsynlig at det hadde blitt trukket opp igjen av den nevnte "bøtta".

Et alternativ til det ensyklopediske og kontekstuelle paradigmet er det estetiske, som MuCEM så vel som Branly har prioritert. I parentes bemerket ser vi det samme når det gjelder franske museers behandling av religiøse objekter, som i den nyetablerte Louvre-avdelingen for islamsk kultur (Rogan 2013). I Branlys tilfelle innebærer det primært å nedtone gjenstandenes kontekst og se dem som objekter med en estetisk egenverdi, å anskue dem som kunstobjekter. Det samme kan observeres i MuCEM, men det mest slående her er hvor tungt flere av utstillingene hviler på les beaux arts eller kunstobjekter, i form av malerier men også kunstfotografi og skulptur. Et markant trekk ved utstillingene høsten 2013 er det betydelige innlånet av kunst fra Louvre og andre kunstmuseer. Forskjellen mellom $\mathrm{Mu}$ CEM og Branly på dette feltet - en forskjell som også bidrar til å forklare hvorfor Branly kom raskt på plass og MuCEM sent - er at Branly tidlig gikk inn for den estetiske linjen, mens MuCEM ble tvunget til å tenke kunst på et sent tidspunkt. Også det nye nasjonalmuseet for vitenskap, kunst og samfunn som skal åpne i Lyon høsten 2014, le Musée des Confluences, annonserer at kunst skal utgjøre en vesentlig bjelke i museumskonseptet.

Dette peker mot et annet fellestrekk ved de nye museumsetableringene i Frankrike i senere tid (kanskje kunstmuseene unntatt), nemlig flerfagligheten. Mens det gamle $\mathrm{MdH}$ var et rendyrket antropologisk museum, ble arvtakeren Branly et "antropologisk kunstmuseum" ledet av en kunsthistoriker. Og mens det gamle MNATP var et etnologisk-folkloristisk museum (i senere tid med et tilsnitt av sosiologi i den frittstående forskningsenheten (EF), erklærer MuCEM nå at utstillingene skal være tverrfaglige og åpne for antropologer og sosiologer, arkeologer og historikere, kunsthistorikere og - kunstnere (Suzarelli [2013]). Denne overgangen er den kanskje mest grunnleggende endringen ved disse museene. $\mathrm{MdH}$ var en gang den moderne franske antropologiens vugge og disiplinens kunnskapsbase, slik MNATP var det for etnologien. For begge disipliners vedkommende har det vitenskapelige tyngdepunktet forflyttet seg fra museene til universiteter og egne forskningssentre. 
Dette betyr ikke at MuCEM og Branly ikke ønsker å vektlegge betydningen av forskning. Men forskningen skal krysse disiplingrensene, og en konsekvens av flerfagligheten er ved begge museene en vekt på dialog og formidling. Disse institusjonene er lite begeistret for begrepet "museum" og foretrekker betegnelsen "dialoginstitusjon". Begge viser gjennom sine aktivitetskalendre en vilje til å snakke mindre til og mer med publikum.

Så kan man spørre: Hva var atypisk ved $\mathrm{Mu}-$ CEM-prosjektet? Da prosjektet var vel i havn, spurte jeg en av museets ledere, som har fulgt prosessen tett helt siden 1990-tallet, om hva som etter hans mening egentlig hadde vært kjernen i problemet. Svaret var kort og enkelt, men tankevekkende: "Det var vanskelig å vite hvem som var for og imot i embetsverket. MuCEM manglet en 'fadder' på høyt nivå som Pompidou for Beaubourg, som Mitterand for le Grand Louvre, eller som Chirac for Branly."18

Det kan fortone seg merkelig at en president har direkte makt i museumsspørsmål, men med den betydning kunst og kultur har for fransk identitet, er det en god tradisjon for dette (Poirrier 2006, 2010). Beauborg (Pompidou-senteret) var George Pompidous personlige prosjekt, Musée d'Orsay var Valéry Giscard d'Estaings og Grand Louvre François Mitterands personlige prosjekter. Og Branlymuseet er et kroneksempel på en fransk presidents (Jacques Chiracs) personlige styring av et kulturprosjekt (Price 2007, 2011, Rogan 2008, 2010).

Disse kunstmuseene er dessuten en komponent i fransk utenrikspolitikk (Rogan 2013). Som sådan inngikk også MuCEM i Sarkozyadministrasjonens utenrikspolitiske ambisjoner om en middelhavsunion ledet av Frankrike - et prosjekt som for øvrig falt i fisk.

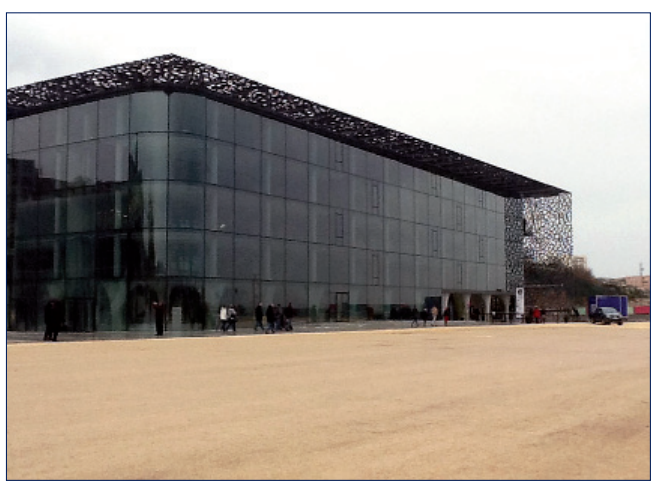

Fig. 5. MuCEMs nye hovedbygning - fasaden, i glass og spesialbetong. Fra overleveringen av bygget. Januar 2013. Foto: Bjarne Rogan.

MuCEM anno 2013 fremstår altså som et vellykket kulturprosjekt - som møteplass og dialoginstitusjon. Men en liten følelse av ambivalens er uunngåelig, spesielt med tanke på forholdet mellom intern og ekstern faglig kompetanse. Størrelsen og den faglige profilen på den vitenskapelige staben er svært langt fra optimal med tanke på forskning, innsamling og fornyelse av utstillinger og andre aktiviteter $\mathrm{i}$ årene fremover. Denne institusjonstypen, med relativt få vitenskapelig og faglig ansatte, forutsetter et samarbeid med eksterne eksperter. Det har MuCEMs forbilde - Branly-museet, som er situert i hjertet av Paris - langt på vei klart når det gjelder forskning og utstilling. Forhåpentligvis lar det seg gjøre også i Marseille. Og trolig er en slik løsning bedre enn den profilen MNATP fikk, med en fast forskningsavdeling der de vitenskapelige etter hvert gikk sine egne veier.

Den uroen som likevel oftest luftes, gjelder samlingene. Det nye museets profil er dårlig tilpasset de egne samlingene, som har tyngdepunkt i det midtre og nordlige Frankrike og 
det nordlige Europa. Storparten av samlingene som ble arvet fra MNATP eller overdratt fra $\mathrm{MdH}$ ligger nå brakk i magasinene. Vi har altså å gjøre med et stort museum som starter opp nesten uten relevante samlinger, og uten planer for brede innsamlingsprosjekter. Avhengigheten av innlån fra andre museer er stor, og ikke minst når det gjelder kunst, som jo skal være en av bærebjelkene. Etter min mening er dette museets akilleshæl. Museet må også i langt større grad enn tidligere kjøpe inn kompetanse på scenografi, fra utstilling til utstilling.

MuCEMs suksess så langt ligger på dialogsiden. Samtidig legger museet opp til et langt mer ambisiøst publikumsorientert program enn samlings- og forskningspolitikken kan bære. Museet gjør seg på den måten mer avhengig av eksterne krefter enn tidligere. Hvordan vil det gå, når nyhetens interesse ikke lenger kan bære prosjektet alene? Det sies at suksessprosjektet og forbildet Branly, som har hatt ca. ti millioner besøkende i sine første seks år, nå opplever et fallende besøkstall ... ${ }^{19}$

\section{ETTERTANKE}

Der sto jeg da, på åpningsdagen den 4. juni 2013 i Marseille, og funderte over min rolle i dette prosjektet, en rolle som opprinnelig hadde hvilt på min kompetanse som etnolog og min kjennskap til det nordlige Europa og museer for folkekultur. I løpet av det drøye tiåret jeg hadde vært med på prosjektet, var folkekultur byttet ut med kunst og kultur i stor bredde, etnologien var utvidet med en bred vifte disipliner, og Europa satt på sidelinjen til fordel for middelhavsregionen. Et domenetap for fransk etnologi? En god del franske etnologer mener det. Denne følelsen ble kraftig forsterket av siste års heftige debatt om reorgani- seringen av studietilbudene ved universitetene, der etnologi sto i fare for å miste sin posisjon som en selvstendig studieretning på bachelornivå (licence) og bli organisert som en 2. og 3. års spesialisering under "Samfunnsfag" eller "Sosiologi" Først i januar 2014 ble det endelig klart at franske universiteter får tilby en nasjonal bachelorgrad med betegnelsen "Sciences de l'homme, anthropologie, ethno$\operatorname{logie"}{ }^{20}$

Men det var en annen ting som opptok meg like mye. Som invitert sto jeg bare noen meter fra Frankrikes nyvalgte president François Hollande og Marseilles mangeårige borgermester Jean-Claude Gaudin og lyttet til de politiske talene. Av Gaudin, som i et muntert samvær en gang fortalte oss at han ikke stolte på politikere som ikke hadde stor mage underforstått: Alle viktige avgjørelser tas ved lunsjene og middagene. $\mathrm{Og}$ av presidenten selv, som snakket om alt annet enn museer og kultur. Ingen av dem takket hovedaktøren Michel Colardelle, som hadde hatt de fleste ideene - om et museum utenfor Paris, om et museum som omfattet mer enn det franske, om et museum som går i dialog med sin samtid, og som i mer enn ti år hadde arbeidet utrettelig for å få museet på plass. Hans navn ble aldri nevnt. Borgermester Gaudin visste nok det meste. Men presidenten - hva har hans embetsverk fortalt ham om denne prosessen? Trolig ingen ting.

\section{LITTERATUR}

Boël, Denis-Michel, Jacqueline Christophe \& Régis

Meyran (red.) 2009. Du folklore à l'ethnologie.

Paris: Éditions de la MSH.

Chevallier, Denis \& Aude Fanlo (red.) 2013.

Métamorphoses des musées de société. La

Documentation française. 
Colardelle, Michel (red.) 2002. Réinventer un musée, le musée des Civilisations de l'Europe et de la Méditerranée à Marseille, Projet scientifique et culturel. Réunion des Musées Nationaux.

Gorgus, Nina 2003/1999. Der Zauberer der Vitrinen. Zur Museologie Georges Henri Rivières. Münster: Waxmann Verlag. (Fransk utg. 2003: Le magicien des vitrines. Le muséologue Georges Henri Rivière. Paris: Éditions de la MSH.)

Mazé, Camille 2008. "Des musées de la nation aux musées de l'Europe. Vacillement, maintien ou renforcement d'un modèle?" I Anne-Solène Rolland \& Hanna Murauskaya (red.). Les musées de la nation. Créations, transpositions, renouveaux. Europe, XIXe-XXIe siècles. Paris: l'Harmattan, 123-142.

Mazé, Camille 2010. Mettre l'Europe au musée: Une affaire de l'État? Ethnographie et sociohistoire du chantier 'des musées de l'Europe' (1980-2010). Thèse de science sociale, EHESS-ENS.

Mazé, Camille 2013. ”Du MNATP au(x) MuCEM. Les vicissitudes du musée national français d'ethnologie." I Camille Mazé, Frédéric Poulard \& Christelle Ventura (red.). Les Musées d'ethnologie. Culture, politique et changement institutionnel. Paris: CTHS, 177-203.

Mazé, Camille, Frédéric Poulard \& Christelle Ventura (red.) 2013. Les Musées d'ethnologie. Culture, politique et changement institutionnel. Paris: CTHS.

Poirrier, Philippe 2006. Art et pouvoir, de 1848 à nos jours. Le Centre National de documentation pedagogique: Maison edition du Ministère de l'Éducation nationale (France).

Poirrier, Philippe 2010. L'État et la culture en France au XXe siècle. Paris: Le Livre de Poche. 3e édition augmentée.

Price, Sally 2007. Paris Primitive - Jacques Chirac's Museum on the Quai Branly. Chicago \& London: The University of Chicago Press. (Fransk utg. 2011).
Rogan, Bjarne 2003a. "Mot et postnasjonalt og et postkolonialt museum. Et fransk museumslandskap i forvandling." I Arne Bugge Amundsen, Bjarne Rogan \& Margrethe C. Stang (red.). Museer i fortid og nåtid. Essays $i$ museumskunnskap. Oslo: Novus, 279-299.

Rogan 2003b. "The emerging museums of Europe." Ethnologia Europaea 33:1, 51-60.

Rogan 2003c. "Towards a post-colonial and a postnational museum. The transformation of a French cultural landscape." Ethnologia Europaea 33:1, 37-50.

Rogan, Bjarne 2008. "Branly - postkolonialt eller nykolonialt museum. Eller: Hvorfor og hvordan den Edle Ville lever i beste velgående i hjertet av Paris." Tidsskrift for kulturforskning 4, 85-98.

Rogan, Bjarne 2010. ”Tingenes transformasjoner i museet. Mellom kontekst, språk, estetikk og politikk." I Bjarne Rogan \& Arne Bugge Amundsen (red.) 2010. Samling og museum. Kapitler av museenes historie, praksis og ideologi. Oslo: Novus, 255-276.

Rogan, Bjarne 2013. ”Louvre, Islam og det trehodete trollet. Om makt og politikk, sekularisme og annet i franske museer." Tidsskrift for kulturforskning 1, 23-40.

Rolland, Anne-Solène \& Hanna Murauskaya (red.) 2008. Les musées de la nation. Créations, transpositions, renouveaux. Europe, XIXe-XXIe siècles. Paris: l'Harmattan.

Segalen, Martine 2005a. Vie d'un musée 1937-2005. Paris: Stock.

Segalen, Martine 2005b. "Un regard sur le Centre d'ethnologie française." La revue pour l'histoire $d u$ CNRS. Nettversjon: http://histoirecnrs.revues.org/1683

Segalen, Martine 2013. "Limpossible musée des cultures de la France. Le cas du musée national des Arts et Traditions populaires." I Camille Mazé, Frédéric Poulard \& Christelle Ventura 
(red.). Les Musées d'ethnologie. Culture, politique et changement institutionnel. Paris: CTHS, 155-175.

Suzzarelli, Bruno (red.) [2013]. Projet scientifique et culturel du MuCEM. Marseille: MuCEM.

Tornatore, Jean Louis 2004. "La difficile politisation du patrimoine ethnologique." Terrain 42, mars 2004. Nettversjon:

http://terrain.revues.org/1791

\section{UTRYKT KILDEMATERIALE}

Deltakende observasjon (møtedeltakelse, seminarer m.m. ved MuCEM) i årene 2001-13, samt samtaler med personalet både ved det gamle MNATP siden 1980-tallet og ved MuCEM frem til 2013 (se note 1).

\section{Noter}

1. Av litteratur for øvrig om MuCEMs tilblivelseshistorie kan nevnes Chevallier \& Fanlo 2013, Colardelle 2002, Mazé 2008, 2010, 2013, Rogan 2003a, b, c.

2. Jeg skylder å gjøre klart for leserne mitt forhold til MNATP/MuCEM. Jeg har kjent museets ledere og staben fra 1980-tallet til i dag, og flere av dem er blitt personlige venner. Jeg satt i tolv år i $\mathrm{MuCEMs}$ (nokså inaktive) vitenskapelige råd, og like mange år i rådets (mer aktive) styre og i museets innkjøpskomité. Jeg har deltatt på et femtitalls av museets interne møter. Alt dette har gjort vurderingene både lettere og vanskeligere. Det har vært et privilegium å komme så nær innpå en kulturpolitisk prosess, med langt mer muskelbruk enn jeg er vant til fra Norge. Min nærhet til stoffet kan naturligvis innebære subjektive vurderinger og erindringsforskyvninger.

3. Av tungvektere blant nykomlingene kan nevnes Branly-museet (2006), Centre Pompidou Metz (2010), Islam-museet i Louvre (2012) og Louvre Lens (2013). Og høsten 2014 skal Musée des Confluences åpne dørene i Lyon.
4. Temaene for forskningsprosjektene fremgår av tidsskriftet Terrain, som la Mission etablerte fra 1983.

5. Kilde: Segalen 2005a samt egne samtaler med Jean Guibal gjennom flere år.

6. Se http://www.euromediterranee.fr

7. Dvs. kontroll av samlinger og restaurering, vitenskapelig virksomhet, sikkerhet, utadrettet virksomhet og samfunnskontakt, felles kataloger og digitalisering.

8. Diverse samtaler med Michel Colardelle, Jean Guibal og Denis Chevallier. Sistnevnte var visedirektør og etter Colardelles avgang leder for museets avdeling for forskning og undervisning.

9 President Nicolas Sarkozy prøvde å sette spørsmålet om fransk identitet på dagsordenen, blant annet gjennom et Maison de l'Histoire de France (MHF) - et Senter for fransk historie. Men etterfølgeren François Hollande satte en stopper for dette prosjektet.

10. Kostnadene var anslått til ca. 1,5 milliarder Nkr. Den franske stat skulle bidra med omtrent halvparten av kostnadene, og byen, regionen og et næringslivskonsortium med resten. Også dette var en kronglete prosess, som det ikke er anledning til å gå inn på her.

11. Samtaler med flere av MuCEMs ansatte, høsten 2013.

12. Samtale med MuCEMs nåværende forskningsleder Denis Chevallier, som var Colardelles NK gjennom mange år, 16. oktober 2013.

13. Samtale med konservator Myriam Delledalle, 18. oktober 2013.

14. Min egen plass i både vitenskapelig råd, styre og innkjøpskomité hvilte på forutsetningen om et Europa-museum.

15. Kilde: Brev fra Museumsdirektoratet til Thierry Fabre, sitert bl.a. i Mazé 2013, s. 197. Se også brev av 28. juli 2010 fra kulturministeren til Bruno Suzzarelli, trykket i Suzzarelli [2013], 109-111. 
BJARNE ROGAN

20 16. Brev av 28. juli 2010, som noten over.

17. Diverse intervjuer i aviser og TV-programmer, senest borgermester Jean-Claude Gaudins uttalelser på TV-kanalen France3 den 1. desember 2013.

18. MuCEMs forskningsleder Denis Chevallier, 16. oktober 2013.

19. Muntlig opplysning ved Branlys forskningsdirektør, oktober 2013.

20. Se blant annet flg. nettsteder (lest 30. mars 2014):

http://classes.blogs.liberation.fr/soule/2013/

07/universite-l-ethnologie-et-l-anthopologieont-peur-de-disparaitre-.html http://fcuni.canalblog.com/archives/ 2014/02/03/ 29108785.html http://fcuni.canalblog.com/archives/ 2014/02/03/ 29108785.html

Bjarne Rogan, dr.philos., professor ved Universitetet i Oslo

Senterleder ved Centre franco-norvégien en sciences sociales et humaines, FMSH, Paris bjarne.rogan@ikos.uio.no

Institutt for kulturstudier og orientalske språk Box 1010 Blindern

NO-0315 Oslo, Norge 